\title{
Acceptability of Endometrial Polyp Resection under Local Anaesthesia
}

Abeywardena $\mathrm{AJ}^{1}$, Sivasuriam $\mathrm{A}^{2}$

\begin{abstract}
Introduction: New evidence is emerging to suggest that outpatient endometrial polyp removal under hysteroscopic guidance by morcellation with local anaesthesia is non-inferior to in patient polypectomy under general anaesthesia. However, evidence on its acceptability warrants further evaluation.
\end{abstract}

Objective: To assess the patient's acceptability of endometrial polyp resection under local anesthesia in an outpatient setting.

Methodology : A prospective cohort study was carried out for three months on all patients who underwent this procedure under local anaesthesia in a secondary care unit in the United Kingdom. Intra-operative and post-operative acceptability was assessed by a standard questionnaire filled immediately after the procedure, before discharge and on the first post-operative day.

Results : Fifty patients underwent this procedure. The mean age was 56.48(range3683). Complete resection of the polyps was achieved in $94 \%$ of the patients, while $6 \%$ had partial resection without total failure. Average, intra operative, immediate post operative and day 1 post operative pain scores were $2.38,1.44$ and 1.38 respectively and were in the mild category of the Discrete Quantitative Pain Verbal Rating Scale. Seventy eight percent of the patients were totally satisfied with the procedure while $14 \%$ and $8 \%$ were generally and fairly satisfied. None expressed that the procedure was unacceptable. Ninety four percent opted to recommend the procedure to a friend while $96 \%$ of patients expressed their willingness to undergo the procedure under local anesthesia, if they were to have another resection of the polyp.

Conclusion: Outpatient hysteroscopic polyp resection by morcellation under local anesthesia is well tolerated and accepted by patients in an outpatient setting.

Keywords: Out patient hysteroscopy, Morcellation of Endometrial Polyps, Local Anesthesia

\section{INTRODUCTION}

Abnormal uterine bleeding affects women of all ages and is the commonest gynecological reason for referral to secondary care ${ }^{(1)}$.

${ }^{1}$ International Training Fellow in the Prince Charles Hospital

${ }^{2}$ Consultant in Obstetrics and Gynaecology at the Prince Charles Hospital

Correspondence: Achala J Abeywardena $M B B S, M D, M R C O G$

Email-achala_abeywardena@yahoo.com Achala.Abeywardena@wales.nhs.uk

Competing interests: The authors report no conflict of interest
Endometrial polyps are defined as localised hyperplasic overgrowths of the endometrial glands and stroma projecting from the surface of the endometrium. They accounts for 24 to $41 \%$ of abnormal uterine bleeding according to various population studies ${ }^{(2,4,5)}$. The current practice of surgical removal of the symptomatic endometrial polyps is evidence based ${ }^{(6,7)}$.

Traditionally, polyp removal under general anaesthesia is offered to patients who are diagnosed with endometrial polyps. The more recent advances in endoscopic technology and ancillary instruments have facilitated the development of operative hysteroscopic procedures in an outpatient setting ${ }^{(8)}$. Furthermore, new evidence suggests that outpatient endometrial polyp removal under hysteroscopic guidance by morcellation with local anaesthesia is noninferior to in patient polypectomy under general anaesthesia ${ }^{(5,6,7)}$. This also has the added advantage of treating the patient at the time of diagnosis with many clinical and nonclinical benefits such as possibility of obtaining targeted tissue biopsies, avoidance of risk of general anaesthesia, low procedure related cost, less hospital appointments, least time away from home and quicker return to work $^{(9,10,11,12,13)}$.

However, the patient's acceptability and feasibility is not well understood (14). This study aims to assess the patient's acceptability in a secondary care setting in the United Kingdom.

Our unit adheres to the following steps in performing endometrial polyp resection under local anaesthesia.

- Informed written consent is taken following verbal and written information.

- Analgesics are prescribed to be taken one hour prior to the procedure.

- Patients undergo the procedure in a quiet room with adequate privacy.

- Patients are placed in the lithotomy position.

- The procedure is performed under sterile conditions.

- A chaperone is with the patient while procedure is being done.

- Following the gentle placement of Sims speculum, 4-5 ampoules of Prilocaine Hydrochloride 2\% without Adrenaline is given to establish intracervical or para-cervical block.

- If necessary, the dilatation of cervix is done. This is usually up to 7 or 8 Hegar.

- Hysteroscopy is performed and photographs are taken of any abnormalities, inclusive of the polyp 


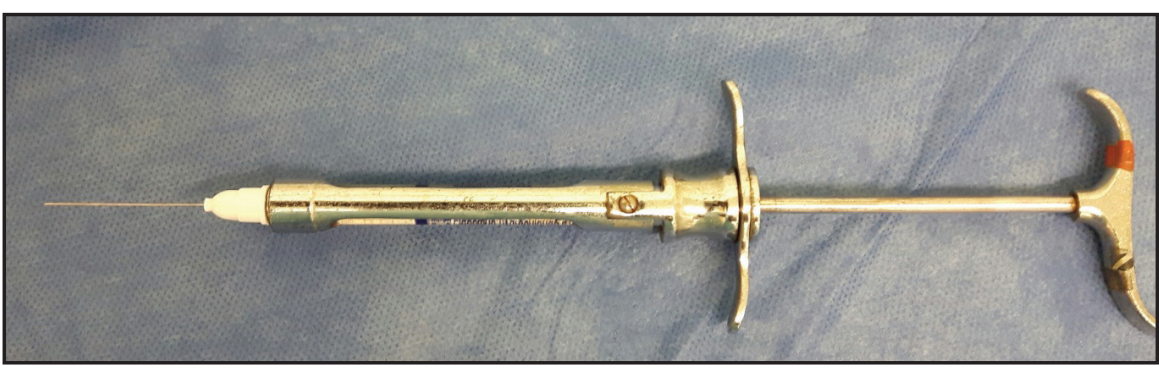

The injection needle used for injecting loaded local anesthetic vials

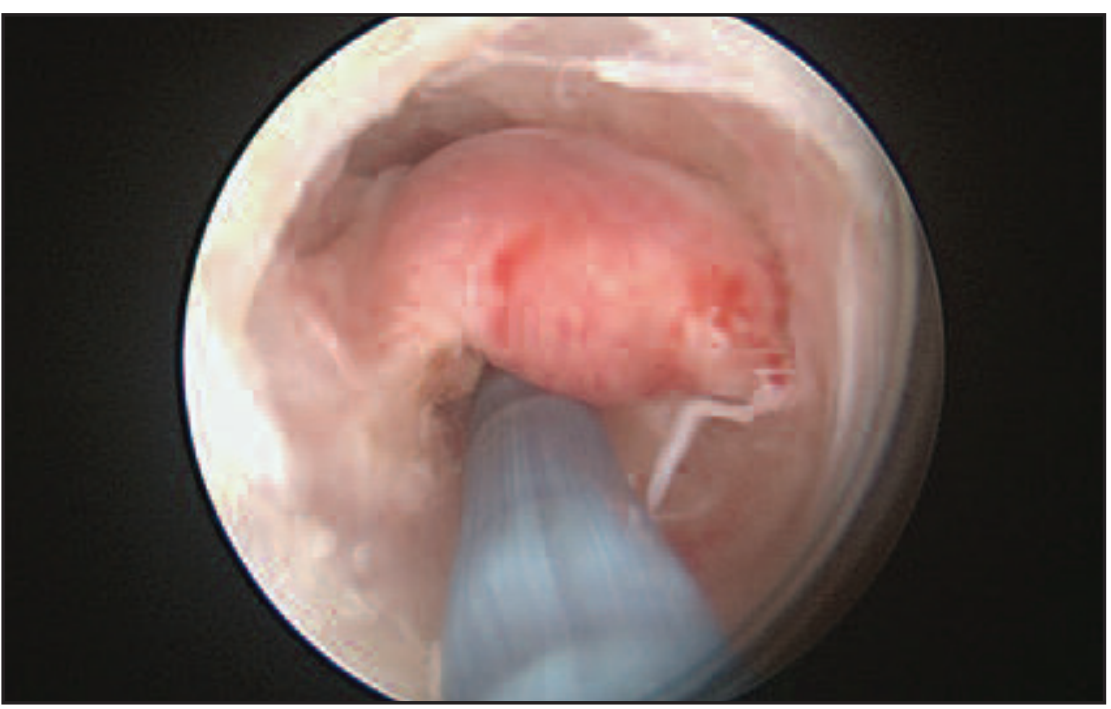

Picture of polyp section by morcellation

- Outflow channel is then removed and replaced with a morcellator of a chosen size. This hysteroscopic tissue removal system resects and removes tissue by suction.

- Operating pressure is maintained at around $70 \mathrm{mmHg}$ but can be increased to $80-100 \mathrm{mmHg}$, if necessary.

- The patient is kept in the recovery room following the procedure and assessed by an experienced member of the staff prior to discharge.

We designed a prospective cohort study and trained all members involved in the study to minimise variations in data collection. Our main objective was to assess the patient's acceptability of endometrial polyp resection under local anesthesia in an outpatient setting.

Intra operative and postoperative pain scores, rating of acceptability of the procedure, recommendation of the procedure to a friend and willingness to undergo the same procedure if a need arises were considered as the main outcome measures ${ }^{(7,15)}$. after the procedure for intra-operative perceptions and prior to discharge for immediate postoperative perception. Further, a telephone conversation with each patient was carried out to determine perception on the first post-operative day.

Quantification of pain was made by means of the Discrete Quantitative Pain Verbal Rating Scale (VRS) that varies from 0 to 10 (equivalent to no pain and the worst pain experienced respectively) ${ }^{(16,17)}$.

All statistical analysis was done by IBM SPSS statistics version 24.0.

\section{RESULTS}

Fifty patients underwent the procedure under local anaesthesia.

The mean age of the population studied was 56.48 years. Fifty eight percent $(29 / 50)$ were postmenopausal. Average BMI was 32.58 , with $58 \%$ of the population above BMI 30. Forty two percent $(21 / 50)$ of women were on long-term medication prior to this procedure, out of which $12 \%$ $(6 / 50)$ were on anticoagulants. They were managed according to the specialised advice from the haematologist.

Twenty two percent (11/50) of the population had undergone a previous cervical procedure that had mainly been LLETZ. _

Most of patients who had the polyps resected presented with post-menopausal bleeding which was $54 \%(27 / 50)$. This was followed by heavy menstrual bleeding in $28 \%(14 / 50)$ and inter menstrual bleeding in $20 \%(10 / 50)$. Ultrasound correctly identified $44 \%$ to be polyps prior to hysteroscopy.

All had premedication one hour prior to standard questionnaire filled immediately

Table1. Level of pain for each step of the procedure

\begin{tabular}{|l|l|lcc|}
\hline \multirow{2}{*}{ Procedure } & Average & \multicolumn{3}{|l|}{ VRS classification } \\
& pain score & \multicolumn{4}{|l|}{ Mild } & Moderate Severe \\
& $0-4$ & 9 or more \\
\hline Introduction of the speculum & 1.71 & 50 & 0 & 0 \\
\hline $\begin{array}{l}\text { Infiltration of the local anesthetic and } \\
\text { use of the vulsellum }\end{array}$ & 2.55 & 48 & 2 & 0 \\
\hline Cervical dilatation & 3.36 & 47 & 2 & 1 \\
\hline Hysteroscopic resection of the polyps & 1.90 & 50 & 0 & 0 \\
\hline Immediate post operative pain & 1.44 & 50 & 0 & 0 \\
\hline Post operative day1 pain & 1.38 & 50 & 0 & 0 \\
\hline
\end{tabular}


the procedure. A single agent was taken by $62 \%$ of the population while $38 \%$ had two agents.

Approximately $94 \%(47 / 50)$ of the patients had a complete resection of the polyps while $6 \%(3 / 50)$ had partial resection without total failures.

About 20\% of the patients had predominantly fundal polyps while rest had predominantly non-fundal polyps. Average intra operative pain score was 2.38 .

Sub-analysis was carried out to see whether there are differences in average pain scores in different categories of patients who underwent this procedure. There was no significant difference in the average pain score between pre and post menopausal women who underwent this procedure ( $\mathrm{P} 0.73$, CI 0.51- 0.83). The average pain score for the cervical dilatation in women who had previous cervical procedures e.g. LLETZ was compared with women who had never undergone a previous cervical procedure and no significant difference was found (P 0.11,CI0.21-0.65). Furthermore, no significant difference in pain for the resection of polyp by morcellation was identified for fundal or non-fundal polyps (P 0.26, CI 0.25- 0.51) . There was no significant difference in average pain for the complete intra operative procedure irrespective of using single or multiple agents as premedication (P 0.65, CI 0.241.4)

There were no reported incidences of cervical damage or uterine perforation. intra-operatively. nausea, vasovagal attacks and excessive hemorrhage were reported in four, two and one instance respectively, while one each complained of nausea and vasovagal episode on the first post-operative day,

\section{PATIENT SATISFACTION WITH THE PROCEDURE}

Seventy eight percent (39/50) of the patients were totally satisfied with the procedure, while $14 \%$ were generally satisfied and $8 \%$ were fairly satisfied. None expressed that the procedure was unacceptable.

A total of $94 \%$ expressed their willingness to recommend the procedure to a friend, while $96 \%$ of the patients expressed their wiliness to undergo the procedure under local anesthesia, if they were to have another resection of the polyps.

\section{DISCUSSION}

Mean intra-operative pain score in our study was 2.38 which is in the mild category and similar to the mean pain score reported as 2.98 by Bergamo AM et al in their study ${ }^{15}$. The mean pain score reported in the study by NAM Cooper et al is 4.5 , which is in the moderate category of VRS and is higher in comparison to our study ${ }^{7}$. The reasons for these variations may be due to the reason that the study by Cooper et al was carried out in several centres, which had different equipment and techniques. This variation was accepted as a limitation in their study by Copper et $\mathrm{al}^{7}$. However, our study used very similar equipment and protocol to the study by Bergamo ET al ${ }^{15}$.

Acceptability of the procedure in our study was quite similar to that which was reported by multicenter study carried out by Copper et $\mathrm{al}^{(7)}$. Our study revealed that the procedure was totally, generally and fairly acceptable to $78 \%, 14 \%$ and $8 \%$ of patients respectively while Copper et al showed acceptability to $60 \%, 23 \%$ and $15 \%$ respectively. Both showed a very low rate of unacceptability accounting for $2 \%$ and $0 \%$ in Copper et al and the index study (7).

Further both studies showed very high rates of recommendation of the procedure to a friend. These accounted for $94 \%$ in the index study and $92 \%$ in Cooper et al. In the index study, $96 \%$ of the patients expressed the desire to have the same procedure done under local anaesthesia if a need arose. This was $90 \%$ in the study done by Cooper and others.

We could not find any studies that analysed the pain scores for each of the steps of the procedure.Cervical dilatation had the highest pain score (Mean 3.36) and intra-cervical or para-cervical infiltration of local anaesthesia and the use of vulsellum on the cervix had the second highest pain score. Polyp resection by using morcellation had a very low mean pain score of 1.9 , which was close to the mean pain scores of the introduction of the speculum, immediate post operative pain score and post operative day one pain score. These finding will be useful for the patients, clinicians and the policy makers in counselling patients and improving facilities for continuing this service provision.

The following points were noted as the limitations of this study. We did not lay strict criteria for the size and number of polyps resected. Thus, we did not analyze the average time taken for one procedure. This may reduce the level of information necessary for policy makers to decide on the number of patients, which would undergo this procedure in a particular session

The extent of the cost reduction and quickness of return to work were not evaluated in this study.

\section{CONCLUSION}

Out patients hysteroscopic polyp resection by morcellation under local anesthesia has a high success rate and very low level of complications. Patients experience a mild level of intra operative pain and minimal post operative pain. Occurrence of other physical symptoms is rare. Thus, it is a well tolerated and very well accepted by patients in an outpatient setting.

\section{ACKNOWLEDGEMENTS}

We would like to thank the patients who underwent this procedure, Staff of the Hysteroscopy Unit of the Prince Charles Hospital and the Research and the Audit Department CWM of the Taff University Health Board.

\section{REFERENCES}

1. Clark TJ, Godwin J, Khan KS, Gupta JK. Ambulatory endoscopic treatment of symptomatic benign endometrial polyps. A feasibility study. Gynaecol Endosco 2002;11:91-7.

2. Clevenger-Hoeft M, Syrop C, Stovall D, Van Voorhis B. Sonohysterography in premenopausal women with and without abnormal bleeding. Obstet Gynecol 1999;94:516-20.

3. Lasmar RB, Dias R, Barrozo PR, Oliveira MA, Coutinho ES, da Rosa DB. Prevalence of hysteroscopic findings and histological diagnoses in patients with abnormal uterine bleeding. Fertil Steril 2008;89:18037.

4. Nagele F, O'Connor H, Davies A, Badawy A, Mohamed H, Magos A. 2500 Outpatient diagnostic hysteroscopies. Obstet Gynecol. 1996;88:87-92. 
5. Rubino, R.J. Hysteroscopic Office Myomectomy Evaluation (HOME). Journal of Minimally invasive Gynecology , 18 , Issue 6, S26 - S27

6. Lieng M,Istre O,Qvigstad E. Treatment of endometrial polyps; a systematic review. Acta Obstet Gynecol Scand 2010; 89:992-1002.

7. Natalie A M Cooper T Justin Clark, Lee Middleton, Lavanya Diwakar, Paul Smith, Elaine Denny, Tracy Roberts, Lynda Stobert, Susan Jowett, Jane Daniels . Outpatient versus inpatient uterine polyp treatment for abnormal uterine bleeding: randomised controlled non-inferiority study. BMJ 2015;350:h1398

8. Royal College of Obstetricians and Gynaecologists. Best Practice in Outpatient Hysteroscopy. London: RCOG; 2011.

9. Marsh FA, Rogerson LJ, Duffy SR. A randomized controlled trial comparing outpatient versus daycase endometrial polypectomy. BJOG. 2006; 113(8):896-901.

10. Marsh F, Kremer C, Duffy S. Delivering an effective outpatient service in gynaecology. A randomised controlled trial analysing the cost of outpatient versus day case hysteroscopy. BJOG 2004;111:2438.

11. Capobianco G, Vargiu N, Dessole F, Milia L, Dessole S.Office hysteroscopy for uterine intracavitary pathologies: "see and treat" approach. Gynecol Surg 2009;6:S1-S31

12. Timmermans A, Veersema S. Ambulatory transcervical resection of polyps with the Duckbill polyp snare: a modality for treatment of endometrial polyps. J Minimal Invasive Gynecolology 2005;12:379.

13. Nathani F, Clark TJ. Uterine polypectomy in the management abnormal uterine bleeding: a systematic review. J Minim Invasive Gynecol 2006;13:260-8

14. Cooper NAM, Clark TJ. Ambulatory hysteroscopy. The Obstetrician \& Gynaecologist 2013;15:159-66. .

15. Bergamo Angela Mendes, Depes Daniella de Batista, Pereira Ana Maria Gomes, Santana Taciana Cristina Duarte de, Lippi Umberto Gazi, Lopes Reginaldo Guedes Coelho. Hysteroscopic endometrial polypectomy: outpatient versus conventional treatment. Einstein (São Paulo) [Internet]. 2012 Sep [cited 2017 Feb 15]; 10( 3 ): 323-328.

16. Bijur PE, Latimer CT, Gallagher EJ Validation of a verbally administered numerical rating scale of acute pain for use in the emergency department Acad Emerg Med. 2003; 10(4):390-2.

17. Salo D, Eget D, Lavery RF, Garner L, Bernstein S, Tandon K. Can patients accurately read a visual analog pain scale? Am J Emerg Med. 2003;21(7): 515-9. 